\title{
Understanding the Causes and Effects of Stigma and Discrimination in the Lives of HIV People Living with HIV/AIDS: Qualitative Study
}

\section{Babatunde Fatoki}

Department of Medicine, Ajeromi General Hospital, Ajegunle, Lagos, Nigeria

\begin{abstract}
Background: Globally HIVIAIDS is a disease of great public health importance, Nigeria has the second largest burden of the disease in the world and currently about $3.4 \%$ of the general population are HIV positive.

Purpose of the study: The study aims to understand the causes of stigma and discrimination against people living with HIVIAIDS (PLWHA) and the effects of stigma and discrimination on the lives of PLWHA

Methods: The study conducted using focused group discussions among people living with HIVIAIDS, who regularly attends ARV clinic, participants were selected based on the number of years of commencement of ARVs and those that have experienced one form of discrimination or the other. The interviews were transcribed verbatim and both manifest and latent content analysis was applied to analyze the texts.

Findings: Following the analysis, two major themes emerged from the study: (1) Broken relationship and nondisclosure are consequences of stigma and discrimination, (2) Poor information strongly contributes to stigma and discrimination. These two themes were able to bring out the cause and effect of stigma and discrimination on the lives of PLWHA.

Conclusion: Stigma and discrimination has contributed to broken relationship and promotes non-disclosure of HIV status to sexual partners, dissolution of families in Nigeria.

Lack of proper information on the disease and poor education and information among the general public and especially health care workers (HCW) worsens stigma and discrimination.
\end{abstract}

Keywords: HIV; Voluntary; Health Care; AIDS

Abbreviations: HIV: Human Immuno-Deficiency Syndrome; PLWHA: People Living With HIV/AIDS; VCT: Voluntary, Counseling And Testing; HCW: Health Care Workers

\section{Background}

Stigma and discrimination are the reflection of the erroneous perception of the disease and these had led to the poor management and treatment of the people living with HIV/AIDS especially in sub Saharan Africa due to the beliefs about how the disease is contracted especially among adults (commonly heterosexual route).

Since the beginning of the epidemic, more than 60 million people have been infected and almost 30 million people have died of HIV related diseases [1]

Nigeria ranks third in the world among nations with high HIV burden [2], although much emphasis has been done on prevention of the spread of disease and treatment of the disease, there are still a large of people who do not adopt preventive measures and often requires treatment, however shame and societal neglects and non-acceptance has contributed to this lack of progress in both preventive and treatment measures.

The HIV prevalence in Nigeria over the past twenty years has however taken a downward trend with $3.8 \%$ in 1993, then peaking at $5.8 \%$ in 2001 and receded to $4.1 \%$ in 2010 signifying a downward trend [2].

Stigma results in discrediting and loss of dignity and value and tends to label people as being unfortunate, inferior depending on the way it is applied. Discrimination arises from differences that can be consistently labeled and that set up the person as different from the perceived norm and can be based on various factors ranging from race, gender and sexual orientation [3].

HIV related stigma among people living with HIV/AIDS (PLWHA) has been classified into three different types of domain namely perceived, experienced and internalized [4].

Perceived stigma explains the belief that a person will be discriminated or judged in a negative way if their HIV status is made known to others or someone else, experienced or enacted stigma on the other hand explains the actual events of discrimination experienced by PLWHA and internalized stigma refers to the shame and negative selfimage felt by those diagnosed or living with HIV [4].

Perceived and experienced stigma may negatively affects someone's HIV testing, retention of care and adherence through fear that being sited or seen at an HIV clinic, missing work and having to attend appointments or being seen taking medications will expose one's HIV status [4].

Experienced, perceived and internalized stigma may results to

*Corresponding author: Babatunde Fatoki, Department of Medicine, Ajerom General Hospital, Ajegunle, Lagos, Nigeria, Tel: 264817734282; E-mail: fatoksbaba@gmail.com

Received September 23, 2016; Accepted November 07, 2016; Published November 14, 2016

Citation: Fatoki B (2016) Understanding the Causes and Effects of Stigma and Discrimination in the Lives of HIV People Living with HIVIAIDS: Qualitative Study. J AIDS Clin Res 7: 635. doi: 10.4172/2155-6113.1000635

Copyright: (C) 2016 Fatoki B. This is an open-access article distributed under the terms of the Creative Commons Attribution License, which permits unrestricted use, distribution, and reproduction in any medium, provided the original author and source are credited. 
Citation: Fatoki B (2016) Understanding the Causes and Effects of Stigma and Discrimination in the Lives of HIV People Living with HIV/AIDS: Qualitative Study. J AIDS Clin Res 7: 635. doi: 10.4172/2155-6113.1000635

Page 2 of 6

mental disorders like depression, low self-esteem, isolation and feeling of hopelessness or loss of control which can ultimately results in loss of motivation to remain in care and non-adherence to treatment and even suicidal intents [4].

Both stigma and discrimination has huge effect on the management of the disease as it can results in delay in diagnosis and therefore causes delay in entry into treatment and adoption of a healthy lifestyle, causes fear in disclosure of illness to important people in the family that will assist in the management of the disease and also causes restriction in participation involving activities of life and depression [3].

Stigma often occurs when an attribute or a characteristic creates a gap between who we think we are (our actual social identity) and how we are seen by others (our virtual identity) and this gap creates a spoiled identity that often cuts the stigmatized person off from the society and from himself so that he stands as a discredited person against an unaccepting world [5].

Stigma and discrimination causes negative health outcomes for people living with HIV/AIDS (PLWHA) which includes poor treatment adherence, engagement in unsafe sexual behaviors, greater severity of AIDS related symptoms, lower perceived general health, low selfesteem and less health care satisfaction [3].

HIV related stigma and discrimination often reduces the chances of people using condoms, accessing preventive HIV services such as educational meetings and counseling, and stigma and discrimination also worsens existing prejudices and can lead to delayed testing and disclosure of HIV status, accusations, abandonment, partner violence and negligence. Stigma also reduces the quality of life, delay in treatment and reduction in survival among PLWHA and impedes adherence to treatment [6].

HIV/AIDS related stigma and discrimination have been extensively documented among health care workers ranging from HIV testing without consent, breaching of confidentiality, labeling, gossiping, verbal harassment, differential treatment and even denial of treatment, understanding the magnitude and causes of underlying HIV related stigma and discrimination amongst health worker is necessary for developing anti-stigma strategies and programs [7].

The perception that HIV infection is associated with social deviance and immorality may result in greater stigma towards PLWHA $[8,9]$.

Stigma often times is applied to social disgrace and generally recognized and described as an attribute that is deeply and greatly discrediting, that reduces the tagged or bearer from a whole and unusual person to a tainted and discounted individual [10]. Stigma is also used to set the affected persons or groups apart from the normalized social order (we against them) and this isolated implies devaluation [11].

HIV/AIDS stigma and discrimination is often shaped by individual perceptions and interpretations of micro-level interactions, but also by larger social and economic forces [12].

Stigma and discrimination is a social constraint which has significant impact on the life experiences of people, stigma includes prejudice and can results into active discrimination directed towards the social groups and persons to whom they are linked [11].

HIV/AIDS is stigmatizing because it carries many symbolic associations with danger, attribution of contagion, immorality and incurability and punishment for sinful acts is common in many societies [13].
PLWHA are often seen as a reflection of evil and sin, leading to powerful and intense stigma against those who have contracted the disease [14].

The fear of stigma and discrimination limits the efficacy of HIV testing and programs across sub-Saharan Africa [15].

Stigma and discrimination often leads to many consequences for PLWHA and some of these includes poor uptake of maternal health care services by women, fear of health workers getting infected and less provision of health care services by health workers because they consciously take into account the HIV status of patients while attending to them or when being in contact with PLWHA [16] (Figures 1 and 2).

\section{Methodology}

The researcher used qualitative research methods including indepth interviews and focus group discussions to collect relevant information regarding the research topic. Tape recorder was used to collect the data, they were then transcribed into codes, after which they were systematically arranged into categories and themes (Tables 1 and 2).

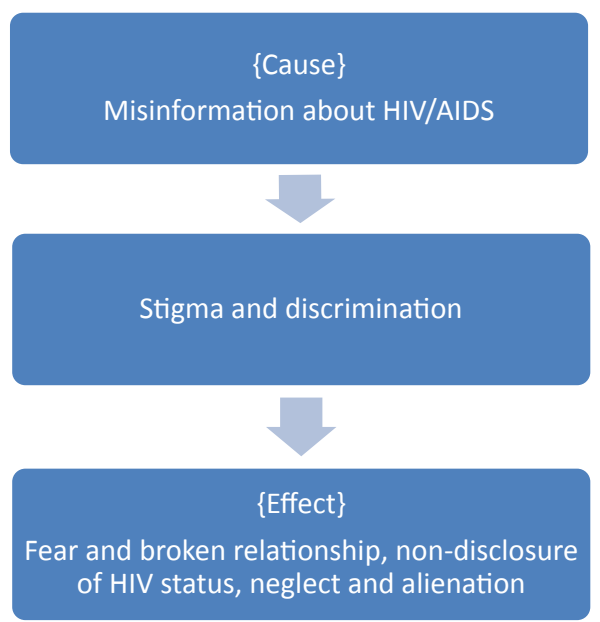

Figure 1: Diagrammatic representation of the cause and effect of stigma and discrimination.

The diagram gives a clear cause and effect of stigma and discrimination in the study, misinformation often leads and fuels more stigma and discrimination in a society where little knowledge and old information about the disease ultimately leads to more stigma and the consequence of stigma and discrimination is dissolution of relationship, fear neglect and alienation, non-disclosure of HIV status which contributes to more spread of the infection

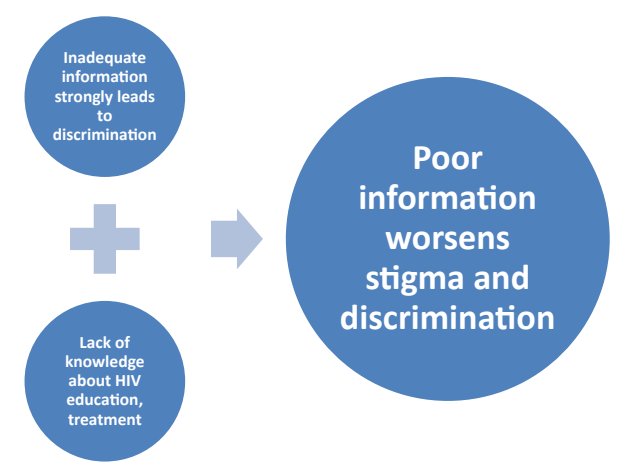

Figure 2: Causes of stigma and discrimination. 
Citation: Fatoki B (2016) Understanding the Causes and Effects of Stigma and Discrimination in the Lives of HIV People Living with HIV/AIDS: Qualitative Study. J AIDS Clin Res 7: 635. doi: 10.4172/2155-6113.1000635

Page 3 of 6

\begin{tabular}{|c|c|c|c|}
\hline Meaning units & Transcribed codes & Categories & Themes \\
\hline $\begin{array}{l}\text { 'I asked some women if they are HIV positive and how will they feel, they said God forbid' FGD } \\
2 \\
\text { 'Immediately people know you are HIV positive, they will not want to associate with you again' } \\
\text { FGD } 1 \\
\text { 'If a person is your friend, there will be some fear and gap but with time they will associate with } \\
\text { you again" FGD1 } \\
\text { 'Like me, my husband does not know I have HIV, because if he does, he will drive me away' } \\
\text { FGD3 'The only person that knows about my status is my sister and mom, unlike my girlfriend when } \\
\text { she got to know about 4years ago, ran away' FGD3 } \\
\text { 'Like me no one knows I have HIV, they will run away if they know I am HIV positive' FGD4 } \\
\text { 'So in disclosing ones HIV status, if you do not have educated people who understands the } \\
\text { nature of the disease, then disclosing it to someone else can cause a lot of problem' FGD } 5 \\
\text { 'like me when I found out that I was HIV positive, and told my fiance,, he did not marry me } \\
\text { because of my HIV status" FGD6 }\end{array}$ & $\begin{array}{l}\text { Denial of HIV status } \\
\text { Fear of association } \\
\text { Hiding of status } \\
\text { Dissolution of } \\
\text { relationship } \\
\text { Hiding of status } \\
\text { Fear of break of } \\
\text { relationship } \\
\text { Dissolution of } \\
\text { relationship }\end{array}$ & $\begin{array}{l}\text { Non-disclosure, fear } \\
\text { and dissolution of } \\
\text { relationship }\end{array}$ & $\begin{array}{l}\text { Broken relationship } \\
\text { and non-disclosure } \\
\text { are consequences } \\
\text { of stigma and } \\
\text { discrimination }\end{array}$ \\
\hline $\begin{array}{l}\text { 'Like my husband got to know he was HIV negative, he ran away from me' FGD } 1 \\
\text { 'It is only my sister that knows about my status, even she also segregates' } \\
\text { 'My husband started discriminating against me, abandoned me, I am sure it is my husband that } \\
\text { infected me' FGD1 } \\
\text { 'Except those that knows about my HIV status, you see some of them running away from me, } \\
\text { some may stay away from me or even refuses to use the same toilet after I use the toilet' } \\
\text { 'Even my husband ran away from me maybe because he found out but then I was having delay } \\
\text { in getting pregnant' FGD7 }\end{array}$ & $\begin{array}{l}\text { Neglect of relationship } \\
\text { neglect } \\
\text { Alienation and } \\
\text { discrimination } \\
\text { Neglect }\end{array}$ & Neglect and alienation & \\
\hline $\begin{array}{l}\text { The rate of discrimination is still very high and may be due to earlier advert based on HIV, } \\
\text { initially it was pictured as a death sentence, they should have used an healthier person to depict } \\
\text { an infected person, so as to let people know that HIV is not a death sentence and that the } \\
\text { infected person still has second chance' FG3 } \\
\text { 'Like when they act movies, they act it, we will feel like killing ourselves, but now it has come } \\
\text { down' FG3 } \\
\text { When people discriminate it is because of lack of education, like me I used to discriminate } \\
\text { before I found out that I was HIV positive' FG } 4 \\
\text { 'They think that if someone has the disease, the person will die immediately, so that is why they } \\
\text { are staying away from us, they are afraid of it, they are scared that when you have it, you will } \\
\text { die immediately' FG5 } \\
\text { 'The bad display both on public and private TV stations and handles and other various forms of } \\
\text { health promotion and messages worsens the image and promoted stigma and discrimination' } \\
\text { FG5 } \\
\text { 'I will start from the when they started the publicity about HIV, it was scary, when they say } \\
\text { something does not have a solution, the propaganda was all about sex, sex, and I found out that } \\
\text { it was not only through sex one can contract the disease, so the initial publicity about HV was } \\
\text { bad, it gave the public a wrong impression and that is why people are scared'FG5 }\end{array}$ & $\begin{array}{l}\text { Misinformation about } \\
\text { HIV } \\
\text { Bad portray of HIV } \\
\text { patients } \\
\text { Negative information } \\
\text { about HIV } \\
\text { Negative display of } \\
\text { information about HIV } \\
\text { Negative information } \\
\text { about HIV }\end{array}$ & $\begin{array}{l}\text { Inadequate information } \\
\text { strongly leads to } \\
\text { discrimination }\end{array}$ & $\begin{array}{l}\text { Poor information } \\
\text { contributes to stigma } \\
\text { and discrimination }\end{array}$ \\
\hline $\begin{array}{l}\text { 'So in disclosing one's HIV status, if you do not have educated people who understands the } \\
\text { nature of the disease, then disclosing one status can cause a lot of problem' FGD5 } \\
\text { 'Stigma and discrimination increases because of lack of knowledge about the disease' FGD6 } \\
\text { 'I think people discriminate because the disease is mostly transmitted via sexual intercourse' } \\
\text { FGD } 7 \\
\text { 'Things have changed compared to about } 10 \text { years ago, because people are beginning to } \\
\text { understand, I believe the level has gone down because of awareness' FGD } 1 \\
\text { 'Information dissemination is still poor and ignorance is still a thing of concern in our } \\
\text { environment' FGD2 } \\
\text { 'In Nigeria, the rate of discrimination is still very high and may be due to deficiency of some } \\
\text { learning skills to educate people on the virus and what to do' } \\
\text { One way I think the discrimination will disappear is when people are enlightened through the } \\
\text { television, movies and even in the hospitals'FGD } 3 \\
\text { 'The stigma and discrimination has reduced now because government has made provision for } \\
\text { better treatment, HIV stigma and discrimination thrives because of lack of knowledge'FGD6 }\end{array}$ & & $\begin{array}{l}\text { lack of knowledge } \\
\text { about HIV Education, } \\
\text { treatment }\end{array}$ & \\
\hline
\end{tabular}

Table 1: Display of how the interviews were analyzed.

Stigma and discrimination $\longrightarrow$ Neglect and alienation

Table 2: Effect of stigma and discrimination.

HIV patients who regularly attend the Heart to Heart clinic at Ajeromi general hospital were selected based on voluntary decision (informed consent and also voluntarily signed consent forms), treatment compliance and meeting up with appointments. Conventional content analysis was adopted to extract both the manifest and latent meaning of the data.

\section{Setting}

The study was conducted in Ajegunle, situated in Ajeromi Ifelodun
Local Government Area in Lagos State; Ajegunle is often described as the 'jungle city', as it is the most populated slum area in Lagos state. It mainly comprises of different multiethnic groups including Ijaw, Ilaje, Urhobo, Hausa, Ibo, and Yoruba. This study was conducted at the Voluntary and Counseling Testing (VCT) clinic at the Ajeromi General hospital. This is a public hospital under the Lagos state ministry of health, and it provides health care to the overwhelming majority of the Ajegunle population. The VCT centre is equipped with voluntary counseling and testing of individuals for HIV infection.

\section{Informants}

The participants were selected through purposive sampling of HIV patient who regularly attends the VCT clinic of Ajeromi general 
Citation: Fatoki B (2016) Understanding the Causes and Effects of Stigma and Discrimination in the Lives of HIV People Living with HIV/AIDS: Qualitative Study. J AIDS Clin Res 7: 635. doi: 10.4172/2155-6113.1000635

Page 4 of 6

hospital. The researcher selected those who were currently attending the HIV clinic and has been on medications and adherent to medications and medical appointments, those that had experienced one form of stigma or discrimination or the other, the participants had gained enough experience to be able to give an in-depth understanding on the subject matter. All subjects were interviewed in groups of between 7-10 participants at the hospital in a very quiet environment until saturation was reached. A total of 7 focused group discussions were performed and they all fulfilled the criteria for inclusion in the study. Saturation was achieved after the $6^{\text {th }}$ interview when there was no new information generated from the interviews; however as a safeguard one additional interview was done.

In order to follow the narratives of the focused group discussions, they have been given identity tags: focus group discussion 1=FGD1, focus group discussion 2=FGD2.

\section{Data Collection}

A semi structured interview guide with open ended questions was used to explore the in-depth understanding of the research topic and its related problems. Each question was followed by a probing question to fully grasp their views on the research topic. The focus group discussions lasted between 30 and $60 \mathrm{~min}$ and were conducted in English and tape recorded by the researcher. The interviews were later transcribed verbatim by the researcher into written text, the informants were individually approached by the researcher who works at a nearby hospital close to the VCT clinic and they all agreed to participate in the study.

The support group of the PLWHA in Ajeromi general hospital was notified and they informed their members, most of which voluntarily participated in the focus group discussions

Ethical approval was received from the ethical committee of the Ajeromi General Hospital, the participants were approached and they all fixed a time period for the focus group discussions to be conducted, the participants were informed about the topic and proper description of the study purpose was made known to them, none of the participants objected to their inclusion in the study as they were well acquainted with the researcher. The topics included in the interview guide involved the participants describing their experiences about stigma and discrimination while in and out of the hospital.

\section{Data Analysis}

After the data collection, both manifest and latent content analysis were used to analyze what the text of the interviews dealt with, and describe the obvious and visible components of the data with the intent of exploring the underlying meaning of the texts [17]. The researcher listened to each interviews one after the other, then the narratives were compressed into condensed meaning units while maintaining the full meaning of the words, after which they were transcribed into codes and this was done for after each interviews after which codes were extracted from the text, similar codes were then selected and transcribed into categories and thereafter into themes with the aim of understanding the underlying meaning and gaining deeper insights into the research topic.

\section{Research Findings}

Two major themes emerged from the study:

\section{Broken relationship and non-disclosure}

This theme explains the significance of non-disclosure and its resulting effect in HIV transmission, the impact of disclosure can be fatal when someone's HIV positive status is exposed to an uninformed and ignorant person causing breakdown of relationship and neglect especially among couples, families and loved ones.

\section{Category A: Non-disclosure, fear and dissolution of relationship}

According to the narratives of the informants in the focus group discussions, various factors encourage non-disclosure of status, most people living with HIV/AIDS (PLWHA).

According to the informants: 'I asked some women if they are HIV positive and how will they feel, they said God forbid' FGD 2.

'Immediately people know you are HIV positive, they will not want to associate with you again' FGD 1.

'If a person is your friend, there will be some fear and gap but with time they will associate with you again" FGD1.

'Like me, my husband does not know I have HIV, because if he does, he will drive me away' FGD3.

'The only person that knows about my status is my sister and mom, unlike my girlfriend when she got to know about 4years ago, ran away' FGD3.

'Like me no one knows I have HIV, they will run away if they know I am HIV positive' FGD4.

So in disclosing ones HIV status, if you do not have educated people who understands the nature of the disease, then disclosing it to someone else can cause a lot of problem' FGD 5.

'like me when I found out that I was HIV positive and told my fiancé, he did not marry me because of my HIV status" FGD6.

Category B: Neglect and alienation: 'Like my husband got to know he was HIV negative, he ran away from me' FGD 1.

'It is only my sister that knows about my status, even she also segregates.'

'My husband started discriminating against me, abandoned me, I am sure it is my husband that infected me' FGD1.

'Except those that knows about my HIV status, you see some of them running away from me, some may stay away from me or even refuses to use the same toilet after I use the toilet.'

'Even my husband ran away from me maybe because he found out but then I was having delay in getting pregnant' FGD7.

According to the narratives of the focus group discussions, the consequence of disclosing one HIV status can be detrimental to one's personal relationship with close ones and hence such information about their HIV status are hidden from people so as to avoid discrimination and segregation, HIV/AIDS is disease that drives a way one's friend especially when such closed ones are not well informed.

Poor information contributes to stigma and discrimination: In the second theme in the research shows that inadequate or poor information among people in the general population and even health care workers results in stigma and discrimination.

Category A: Inadequate information strongly leads to discrimination: According to the narratives from the focus group discussion, earlier public health messages were poor and depicted an 
Citation: Fatoki B (2016) Understanding the Causes and Effects of Stigma and Discrimination in the Lives of HIV People Living with HIV/AIDS: Qualitative Study. J AIDS Clin Res 7: 635. doi: 10.4172/2155-6113.1000635

Page 5 of 6

infected person with bad image ranging from the unhealthy looking malnourished and wasted individual to the bad personality display and hence helped to increase discrimination and the attachment of promiscuity to HIV also tagged HIV positive people as paying for their 'sins'.

'the rate of discrimination is still very high and may be due to earlier advert based on HIV, initially it was pictured as a death sentence, they should have used an healthier person to depict an infected person, so as to let people know that HIV is not a death sentence and that the infected person still has second chance' FG3.

'Like when they act movies, they act it, we will feel like killing ourselves, but now it has come down' FG3.

When people discriminate it is because of lack of education, like me I used to discriminate before I found out that I was HIV positive' FG 4.

'they think that if someone has the disease, the person will die immediately, so that is why they are staying away from us, they are afraid of it, they are scared that when you have it, you will die immediately' FG5.

'The bad display both on public and private TV stations and handles and other various forms of health promotion and messages worsens the image and promoted stigma and discrimination' FG5.

'I will start from the when they started the publicity about HIV, it was scary, when they say something does not have a solution, the propaganda was all about sex, sex, and I found out that it was not only through sex one can contract the disease, so the initial publicity about HV was bad, it gave the public a wrong impression and that is why people are scared' FG5.

Category B: Lack of knowledge about HIV: The study explains the importance of education as a pivotal in the understanding of the disease and its nature, acceptance and the relationship between stigma and discrimination and education.

Some of the narratives of the focus group discussion and interviews explain thus,

'so in disclosing one's HIV status, if you do not have educated people who understands the nature of the disease, then disclosing one status can cause a lot of problem' FGD5.

'Stigma and discrimination increases because of lack of knowledge about the disease' FGD6.

'I think people discriminate because the disease is mostly transmitted via sexual intercourse’ FGD 7.

'Things have changed compared to about 10 years ago, because people are beginning to understand, I believe the level has gone down because of awareness' FGD 1.

'Information dissemination is still poor and ignorance is still a thing of concern in our environment' FGD2.

'In Nigeria, the rate of discrimination is still very high and may be due to deficiency of some learning skills to educate people on the virus and what to do.'

One way I think the discrimination will disappear is when people are enlightened through the television, movies and even in the hospitals' FGD 3.

'The stigma and discrimination has reduced now because government has made provision for better treatment, HIV stigma and discrimination thrives because of lack of knowledge' FGD6.

\section{Discussion}

The findings in the research shows that people in the general population and even some health care workers also stigmatize PLWHA and often can be due to inadequate knowledge and information, which also corroborates similar research in Nigeria by Manjok et al. which shows that among physicians, nurses and laboratory scientist, lack of appropriate knowledge about HIV infection and transmission enhances the negative attitudes of health care workers and often times results in refusal to treat and care for PLWHA [18].

According to this current research, provision of adequateinformation and education can help to reduce stigma and discrimination, other studies also showed similar findings that information based approaches such as written information in a brochure, skills acquisition and building, participatory learning sessions to reduce negative attitudes, counseling and support, creation and strengthening of support groups, regular contact with affected groups, interaction between PLWHA and the general public will go a long way in reducing stigma and discrimination, health education $[5,18]$.

According to a study conducted by Feyissa et al., health care workers who had higher basic knowledge about HIV, training and educational levels had lower stigma scores when compared with those with lower basic HIV knowledge [7].

Similar studies by Audet et al. showed that PLWHA had experienced stigma in multiple ways, occasionally friends avoided personal contacts, co-workers and family members often separated foods and utensils and bosses and colleagues often makes ways to avoid working with those living with HIV and participants in the study who had never experienced discrimination carefully chose to whom they disclose their HIV status in other to avoid discrimination, the experiences and perception that HIV stigma exists in their community led many participants to avoid making new friends in other to ensure their status remain unknown and hidden and this could lead to depression, nondisclosure to sexual contacts/partners and poorer health outcomes [4].

According to Cloete et al. in South Africa, there is some degree of unwillingness experienced in disclosing one's HIV status and results in stigma and discrimination renders PLWHA prone to rejection by families, fear of being rejected from their homes and subjected to violence [19].

According to a study in the Niger Delta area of Nigeria which explored the rate, pattern and barriers of HIV sero-status disclosure in a resource-limited setting, the fear of stigmatization and fear of victimization of confidants spreading the word of accusation and infidelity and of abandonment were all noted as barriers of disclosure of HIV status to close ones or relatives Some of the narratives pointed out that the discrimination against PLWHA is not from outside because people from outside do not know others status, but more in the health care facilities where they know their status, hence effort should be channeled towards training and re-training of HCW, especially nurses, laboratory scientist and doctors [20].

One of the strengths of the study was that the data collection through the focused group discussion with the study participants with diverse life experiences of on stigmatization and discrimination was able to give adequate and required information on the research topic. 
Citation: Fatoki B (2016) Understanding the Causes and Effects of Stigma and Discrimination in the Lives of HIV People Living with HIV/AIDS: Qualitative Study. J AIDS Clin Res 7: 635. doi: 10.4172/2155-6113.1000635

\section{Conclusion}

Stigma and discrimination has contributed to broken relationship and promotes non-disclosure of HIV status to sexual partners, dissolution of families in Nigeria and lack of proper information on the disease and poor education fuels stigma and discrimination.

Despite much efforts that had been channeled towards reducing stigma and discrimination, the problem still persist especially in low resource settings and poorly informed people, it is appalling to see that discrimination still exist within hospital settings which should be examples to the outside world especially among health care workers.

Efforts should be directed towards continuous medical and social education of the health care workers and the general public so as to change the misconceptions and behavior of people toward PLWHA, if we are to arrive at zero new infections we have to ensure that stigma and discrimination is drastically reduced in our society, PLWHA have rights and should be respected and treated equal.

\section{References}

1. United Sates Agency for International Development (2011) HIVIAIDS health profile.

2. National agency for the control of AIDS (NACA) (2014) Women, girls and HIV in Nigeria.

3. Skinner D, Mfecane S (2004) Stigma, discrimination and the implications for people living with HIVIAIDS in South Africa. SAHARA J 1: 157-164.

4. Audet CM, McGowan CC, Wallston KA, Kipp AM (2013) Relationship between HIV stigma and self-isolation among people living with HIV in Tennessee. PLoS One 8: e69564.

5. Stangl AL, Lloyd JK, Brady LM, Holland CE, Baral S (2013) A systematic review of interventions to reduce HIV-related stigma and discrimination from 2002 to 2013: How far have we come? J Int AIDS Soc 16: 18734

6. Scaling up the response to HIV stigma and discrimination (2010) ICRW International centre for research on women and London school of hygiene and tropical medicine 1-3

7. Feyissa GT, Abebe L, Girma E, Woldie M (2012) Stigma and discrimination against people living with HIV by healthcare providers, Southwest Ethiopia. BMC Public Health 12: 522
8. Baunach DM, Burgess EO (2013) HIVIAIDS Prejudice and the American South Sociol Spectr L Mid-South Sociological Association 33: 17-195.

9. Sowell RL, Seals BF, Moneyham L, Demi A, Cohen L, et al. (1997) Quality of life in HIV-infected women in the south-eastern United States. AIDS Care 9 : 501-512.

10. Hardon A, Boonmongkon P, Streefland P (1995) Applied Health Research Manual Anthropology of Health and HealthCare. The Hague: CIP-Data, Koninklijke Bibliotheek, Netherlands.

11. Goffman E (1963) Stigma, roles on the management of spoiled identity. NJ prentice hall, Englewood cliffs 147.

12. Campbell C, Nair Y, Maimane S, Nicholson J. Dying twice: A multi-level mode of the roots of AIDS stigma in two South African communities. Journal of Health Psychology 2007; 12: 403-416

13. Simbayi LC, Kalichman S, Strebel A, Cloete A, Henda N, et al. (2007) Internalized stigma, discrimination, and depression among men and women living with HIVIAIDS in Cape Town, South Africa. Social Science and Medicine 64: 1823-1831.

14. Plummer M, Mshana G, Wamoyi J (2006) The man who believed he had AIDS was cured: AIDS and sexually transmitted infection treatment-seeking behaviour in rural Mwanza, Tanzania. AIDS Care 18: 460-466.

15. Thorsen VC, Sundby J, Martinson F (2008) Potential initiators of HIV-related stigmatization: Ethical and programmatic challenges for PMTCT programs. DevelopingWorld Bioethics 8: 43-50.

16. Maedot P, Haile A, Lulseged S, Belachew A (2007) Determinants of vct uptake among pregnant women attending two ANC clinics in Addis Ababa City: Unmatched case control study. Ethiopian Medical Journal 45: 335-342.

17. Dahlgren L, Emmelin M, Winkvist A (2007) Qualitative methodology for international public health. $\mathrm{OCH}$ media, Umea University 33-47.

18. Manjok E, Smesny A, Essien J (2009) HIVIAIDS related stigma and discrimination in Nigeria, review of research studies and future directions for prevention strategies. Afr J Reprod Health 13: 21-35

19. Cloete A, Strebel A, Simbayi L, van Wyk B, Henda N, et al. (2010) Challenges faced by people living with HIVIAIDS in Cape Town, South Africa, issues for group risk reduction interventions, social aspects of HIVIAIDS and health, human sciences, research council cape town south Africa. AIDS Research and Treatment 2010: 8

20. Akani $\mathrm{Cl}$, Erhabor $\mathrm{O}$ (2006) Rate, pattern and barriers of HIV serostatus disclosure in a resource-limited setting in the Niger Delta of Nigeria. Tropical Doctor 36: 87-89. 